\title{
ЛИЧНОСТНО-ТИПОЛОГИЧЕСКИЕ ОСОБЕННОСТИ СТУДЕНТОВ В СЕТЕВОМ ПОВЕДЕНИИ
}

\author{
Иващенко Александр Васильевич \\ Карабущенко Наталья Борисовна \\ Сунгурова Нина Львовна
}

Теоретическое и эмпирическое исследование выполнены при финансовой поддержке РГНФ, грант № 15-06-10956а «Индивидуально-типологические характеристики личности студентов в информационном пространстве».

Организачия эмпирического исследования осуществлена при грантовой поддержке по инициативным проектам подразделений в РУДН, проект 051316-0-000 «Этнокультурные ценности и мотивационные установки студентов международно-ориентированного вуза»

Одним из перспективных направлений современных психологических исследований является деятельность человека в информационном пространстве. Современное информационно-психологическое пространство расширяет границы личной свободы человека. Интернет-ресурсы представляют возможности в использовании различных информационных источников: полоролевого экспериментирования; вариативности самовыражения и самопрезентации. В этой связи сетевое пространство предстает как информационно-психологическое, где находят свое проявление индивидуальнотипологические характеристики личности участников.

В статье представлены теоретические основания изучения индивидуальности личности студентов в информационно-психологическом пространстве. Проявлениями индивидуальности личности в сетевом взаимодействии являются половые, возрастные характеристики, стаж и уровень владения технологиями, степень интереса, направленность, мотивационные аспекты. Индивидуальные особенности проявляются в психологическом отношении к информационным технологиям. Индивидуальные характеристики реализуются в особенностях протекания сетевой активности, предпочтения тех или иных видов деятельности. Типологический подход к индивидуальности личности в условиях информационного пространства представлен некоторыми авторскими моделями.

Эмпирическое исследование проведено с использованием комплекса методов, психодиагностический инструментарий составили оригинальные и авторские методики. Достоверность результатов подтверждается 
репрезентативностью выборки, применением математической обработки данных. В статье анализируются результаты эмпирического исследования индивидуально-типологических особенностей личности студентов в сетевом взаимодействии. Авторами описаны три типа сетевого поведения студентов-участников Интернет-взаимодействия по характеру и степени вовлеченности. Проведен сравнительный анализ результатов исследования сетевого поведения в зависимости от направления профессиональной подготовки студентов. Структурный и корреляционный анализ выявили устойчивые свойства и взаимосвязи, характерные для разных стратегий сетевой активности. В работе представлены обобщенные профили основных типов сетевой активности с позиции индивидуально-типологических особенностей личности студентов.

Ключевые слова: личность студента, индивидуальность, индивидуальность личности, индивидуально-типологические особенности, сетевая активность, образ Я, информационное взаимодействие, самопрезентация, идентичность, виртуальная идентичность.

\section{Введение}

В контексте современной социальной ситуации развития человека, связанной с глобальным информационным пространством, особую важность и актуальность приобретает комплексный и системный анализ одной из значимых проблем современной психологии - проблема индивидуальности личности. Сегодня можно говорить о расширении границ личной свободы человека, различных возможностях самовыражения, саморазвития, вариативности самопрезентации, индивидуально-личностных проявлениях. В контексте информационно-психологической безопасности поднимаются вопросы, связанные с рисками смещения идентичности, нивелированием индивидуальности личности, формированием нереалистичного образа Я $[14,15]$.

Теоретико-эмпирические подходы к исследованию индивидуальности в психологии показывают сложность и разносторонность в понимании данной категории. В отечественной психологии исследования индивидуальности можно представить несколькими основными направлениями:

- дифференциально-психофизиологическое, изучающее биологические, нейрофизиологические и психофизиологические аспекты индивидуальных различий человека (особенности строения тела, свойства нервной системы, темперамент). Это работы И. П. Павлова, Б. М. Теплова, В. Д. Небылицына, В. С. Мерлина, А. М. Русалова [7, 9, 11];

- личностно-типологическое, связывающее индивидуальность с типологическим своеобразием личности (А. Лазурский, А. И. Крупнов, Э. А. Голубева), 
описывающее индивидуальный стиль деятельности человека (Е. А. Климов,

Г. А. Берулава) $[6,7,10,11]$;

- индивидуальность как единство прочессов и состояний психики, взаи-

модействие внутренней и внешней жизни человека (представлена в ра-

ботах К. А. Абульхановой, А. Г. Асмолова, А. А. Бодалева, Д. А. Леонтьева, И. Н. Семенова, Е. Б. Старовойтенко, В. Д. Шадрикова) [1, 11, 12].

Структура индивидуальности описывается несколькими уровнями.

На первом уровне (биологическом фундаменте личности) представлены индивидные, формально-динамические характеристики (пол, темперамент, задатки способностей, асимметрия полушарий головного мозга). На втором уровне характеризуются предметно-содержательные качества (черты, типы личности, способности, стилевые характеристики поведения). На третьем уровне присутствуют духовно-мировоззренческие характеристики (направленность личности, ценности, убеждения, взгляды, установки) [12].

Проблема индивидуальности изучается нами в контексте психологии личности в информационном пространстве. Знакомство с отечественной и зарубежной литературой показывает, что большое количество публикаций ориентировано на изучение влияния на человека пространства Интернета. В зарубежной психологии следует отметить исследования К. Брод, Д. Верч, Д. Магнуссон, Ш. Текл, К. Янг и др. [18, 19, 21, 22, 23, 24]. В отечественной психологии психологические аспекты освоения человеком информационного пространства рассматриваются в работах О. Н. Арестовой, Ю. Д. Бабаевой, Л. Н. Бабанина, Е. П. Белинской, А. Е. Войскунского, Л. П. Гурьевой, А. Е. Жичкиной, Ю. М. Кузнецовой, О. К. Тихомирова, Н. В. Чудовой, И. С. Шевченко и др. [2, 3, 4, 8, 17].

Использование сетевых возможностей реализации познавательной, учебной, учебно-профессиональной деятельности, общения, развлечения делает пространство Интернета такой средой, где проявляются психологические стратегии поведения разных категорий пользователей, их личностные особенности $[5,14,16,20]$.

Проявлениями индивидуальности личности в сетевом взаимодействии являются половые, возрастные характеристики, стаж и уровень владения технологиями, степень интереса, направленность, мотивационные аспекты. Индивидуальные особенности проявляются в психологическом отношении к информационным технологиям $[15,20]$. Индивидуальные характеристики реализуются в особенностях протекания сетевой активности, предпочтения тех или иных видов деятельности.

Среди разных видов сетевой активности можно выделить три основных вида деятельности: познавательную, игровую и коммуникативную [2]. Им соответствуют определенные личностные изменения: 
- познавательная увлеченность в сфере программирования и телекоммуникаций, переходящая в хакерство;

- компьютерная увлеченность, в том числе играми, посредством Интернета, приводящая к игровой зависимости;

- сетевая коммуникативная увлеченность, проявляющаяся, как крайний вариант, в Интернет-аддикции.

Однако, по мнению А. Е. Жичкиной, следует выделить созидательную деятельность, или деятельность по преобразованию самого Интернета (создание веб-страниц, программирование и т. п.) [4].

В целом, сетевая активность может характеризоваться как глубоко психологически насыщенный, личностный процесс. Предъявление себя, самовыражение, переживание себя в Интернет-пространстве отличается от того, как чувствует, как представляет себя человек в реальном мире, что проявляется в феномене «виртуальной личности». Активные участники, создавая виртуальную личность, намеренно показывают одни свои черты или качества, а о других характеристиках умышленно замалчивают, намеренно скрывая определенные намерения.

Типологический подход к индивидуальности личности в условиях информационного пространства можно представить некоторыми авторскими моделями.

С. А. Смирнов выделяет типы «фигур идентичности», определяемые приоритетами сетевого существования [13]:

- человек-чойсер (choicer) - субъект выбора в нулевой ситуации сети-лабиринта;

- человек-сетевик (networker) - собирательный образ бытования в открытом информационно-коммуникативном пространстве;

- человек-понтифик (от лат. pons - «мост» и facio - «делать») - «наводящий мосты», творящий сети, обустраивающий переход;

- человек-челенджер (challenger) - принимающий вызовы и отвечающий на них в новой ситуации;

- человек-навигатор - проводник по сетевому лабиринту, лоцман [13].

В. Фриндте и Т. Келером предлагается типология пользователей в соответствии с личной значимостью или значимостью принадлежности к социальной группе:

- включенность в виртуальную коммуникацию, в персональную идентичность, или «любители», т. е. такие пользователи, которые интересуются Интернетом с позиции возможности общения, но они не включают в свою идентичность принадлежность к тому или иному сетевому сообществу;

- включенность в Интернет-коммуникацию, представленная в социальной идентичности, или «хакеры». У таких участников сетевой коммуникации 
идентичность включает характеристики, отражающие принадлежность к продвинутым пользователям;

- включенность в виртуальную коммуникацию, которая никакого влияния на идентичность не оказывает, или «прагматики». Они пользуются Интернетом только по необходимости [4].

И. С. Шевченко предлагает типологию пользователей Интернета, исходя из особенностей вариативности самопрезентации:

- пользователи, не обладающие подвижностью, вариативностью самопрезентации в Интернет-общении;

- пользователи, обладающие вариативностью самопрезентаций и проявляющие ее в актуальном общении;

- пользователи, потенциально обладающие вариативностью самопрезентаций как возможной стратегией поведения в Интернет-общении, но актуально не проявляющие ее [17].

Целью настоящего исследования стало выявление личностно-типологических особенностей студентов с разными стратегиями сетевой активности, описание образа Я личности, предпочитающей определенное поведение в Интернет-взаимодействии.

\section{Методика}

В исследовании приняли участие студенты московских вузов разных направлений профессиональной подготовки (гуманитарное и инженернотехническое). Объем выборки составил 260 человек. Средний возраст выборки 20,5 лет. Психодиагностический комплекс составили следующие методики: анкета на изучение целей и предпочтений в использовании информационных технологий (Н. Л. Сунгурова), опросник поведения в Интернете (А. Е. Жичкина), методика личностного дифференциала, пятифакторный личностный опросник Р. МакКрае, П. Коста («Большая пятерка») в адаптации А. Б. Хромова.

\section{Результаты}

По целям использования сети ответы студентов распределились следующим образом. Поисковая активность широко представлена в ответах $63 \%$ респондентов. Интерес к коммуникации посредством сетевых ресурсов указывают 32 \% студентов. Предпочитают реальное общение 36 \% студентов, а 20 \% отмечают для себя виртуальное общение как более комфортное. $44 \%$ не высказали определенного предпочтения в отношении виртуального или реального общения. Около 5 \% опрошенных отметили организационную и творческую деятельность (создание сайтов, сопровождение проектов).

По характеру вовлеченности и степени Интернет-взаимодействия определились три типа сетевой активности студентов по А. Е. Жичкиной [4]. 

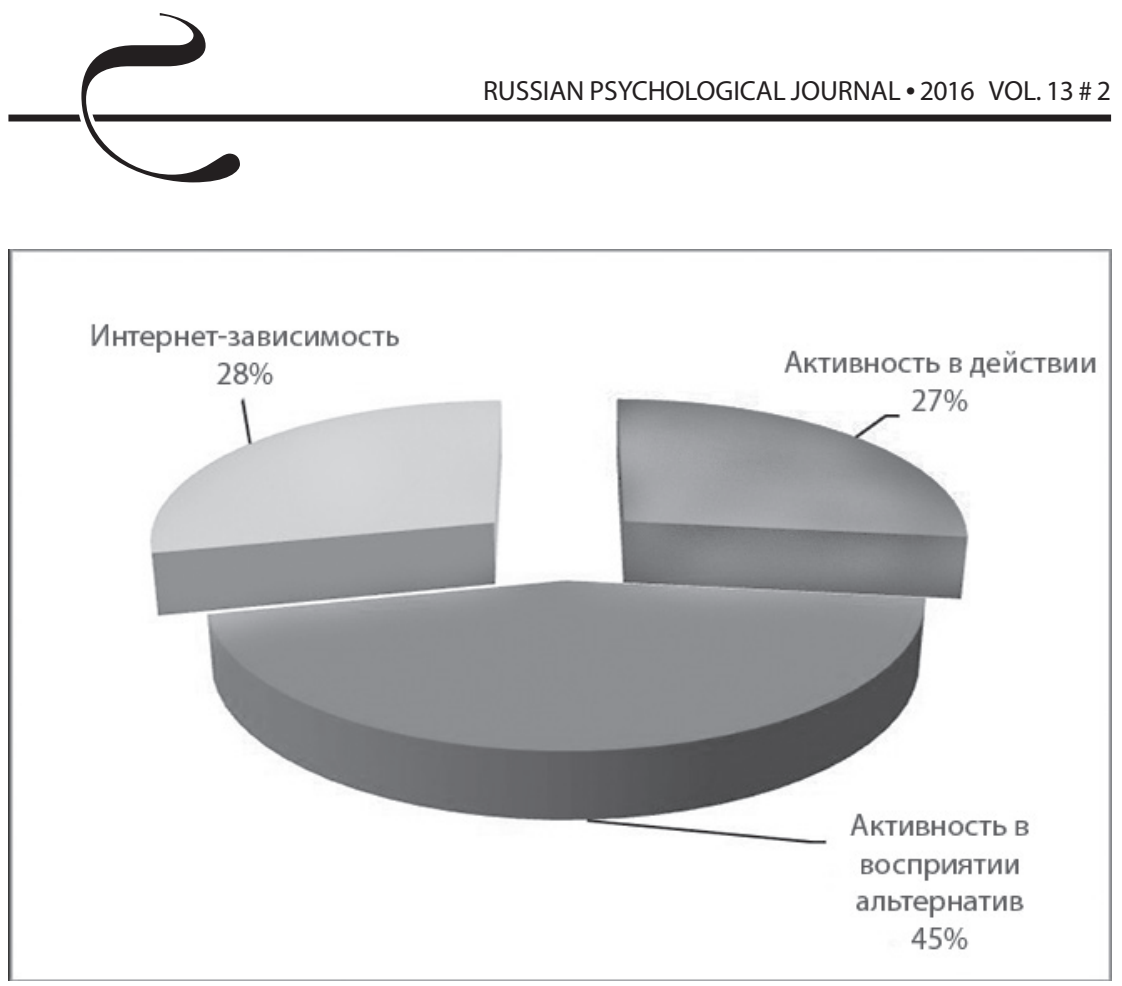

Рисунок 1. Стратегии сетевой активности

«Активность в восприятии альтернатив» характерна для 45 \% студентов. «Активность в восприятии альтернатив» как стратегия сетевого поведения связана с особенностью идентичности участников. Низкие показатели активности в восприятии альтернатив свидетельствуют о значимом стремлении реализовать идеальное Я в Интернете, высокие - о стремлении к самореализации в реальной жизни. Но еще не менее важным для таких пользователей является желание испытать некий новый опыт, который трудно или невозможно испытать в реальном общении.

«Активность в действии» как психологическая стратегия сетевого поведения связана с осуществлением определенных действий, действий в принятии решений - выявилась у 27 \% обучающихся.

Склонность к Интернет-зависимости, выражающуюся в постоянном навязчивом стремлении выйти в Интернет, в потере субъективного контроля над его использованием показали 28 \% опрошенных.

Соотношение шкал по средним рангам распределилось следующим образом: «активность в восприятии альтернатив» $(2,51)$ преобладает в поведении у респондентов над «активностью в действии» $(1,71)$ и «Интернет-зависимостью» $(1,78)$. Математическая обработка данных в SPSS 13.0 с помощью критерия Фридмана выявила статистически значимые различия $\left(\chi_{r}^{2}=118.811 ; p=0\right)$. 
При этом наблюдаются некоторые тенденции, представленные на рисунке 2. Во-первых, имеется преобладание «активности в восприятии альтернатив» для гуманитарного направления, но статистически достоверных различий не выявлено. Во-вторых, по всем стратегиям сетевой активности показатели выше также у студентов гуманитарного направления. Применение критерия Манна-Уитни показало статистически значимые различия: по шкале «Активность в действии» (U = 7125; $\mathrm{p}=0,027)$, по шкале «Активность в восприятии альтернатив» $(U=6415 ; p=0,001)$, по шкале «Интернетзависимость» $(U=6651 ; p=0,003)$. Представляется, что студенты гуманитарного направления (историки, социологи, психологи) в большей мере направлены на сетевое взаимодействие по сравнению с респондентами инженерно-технических специальностей, для которых Интернет-ресурсы менее привлекательны по сравнению со специальным программным обеспечением, используемым в учебно-профессиональной деятельности.

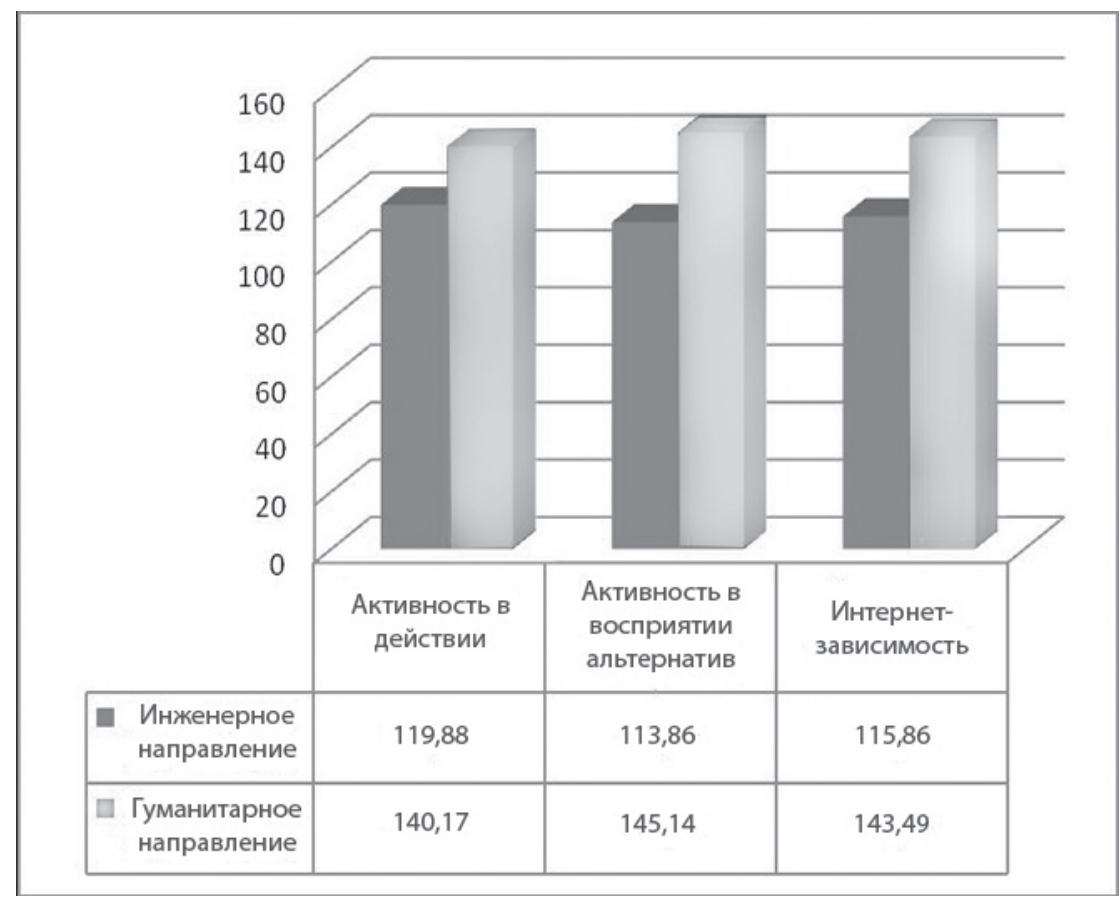

Рисунок 2. Распределение средних рангов стратегий сетевой активности по направлениям подготовки 
В дальнейшей работе использовалась методика личностного дифференциала, которая позволила получить информацию о субъективных аспектах отношений испытуемого к себе, составить обобщенный образ Я.

Для 70 \% студентов, предпочитающих стратегию «активность в восприятии альтернатив», в большей мере характерно доминирование низких значений фактора силы. Для описания личностных особенностей этих студентов применимы следующие суждения: неспособность держаться выбранной линии поведения, зависимость от внешних обстоятельств, недостаточный самоконтроль.

Для 58 \% респондентов - «активных в действии» - доминирующим является фактор активности (низкие значения). Студенты, у которых в поведении преобладает данная стратегия, отличаются экстравертированностью, определенной активностью, спокойными эмоциональными реакциями. Но для данной стратегии активности характерен и фактор силы с низкими значениями у 52 \% студентов, что может говорить о недостаточном самоконтроле, неспособности держаться принятой линии поведения, зависимости от внешних обстоятельств.

У студентов, склонных к Интернет-зависимости, низкие значения имеют фактор активности и фактор оценки, что свидетельствует о неудовлетворенности своим поведением, уровнем достижений, критическом отношении к себе, недостаточном уровне принятия себя, а также указывает на выраженные интровертированные реакции обследуемых, их пассивность и пессимизм.

С позиции качественного анализа положительных и отрицательных характеристик имеем следующее.

Студенты, предпочитающие стратегию «активность в восприятии альтернатив», в основном оценивают себя положительно. Отрицательные характеристики имеют место в категориях: «безответственный», «упрямый», «зависимый».

Большинство респондентов, выбирающих стратегию «активности в действии» в качестве основной, также оценивают себя с позиции положительных качеств: «обаятельный», «добрый», «деятельный», «справедливый», «уверенный», «общительный». К отрицательному качеству была отнесена характеристика «упрямый». А вот по шкале «независимый - зависимый» дала зону неопределенности.

Студенты, проявляющие склонность к Интернет-зависимости, в целом тоже оценивают себя с позиции положительных качеств, однако отрицательные оценки встречаются чаще по сравнению с двумя другими группами. Так, студенты в большинстве оценивают себя с отрицательной стороны по шкалам: «безответственный», «упрямый», «зависимый», «раздражительный».

Распределение результатов исследования по основным факторам «Большой пятерки» для всей выборки в целом можно видеть на рисунке 3. 


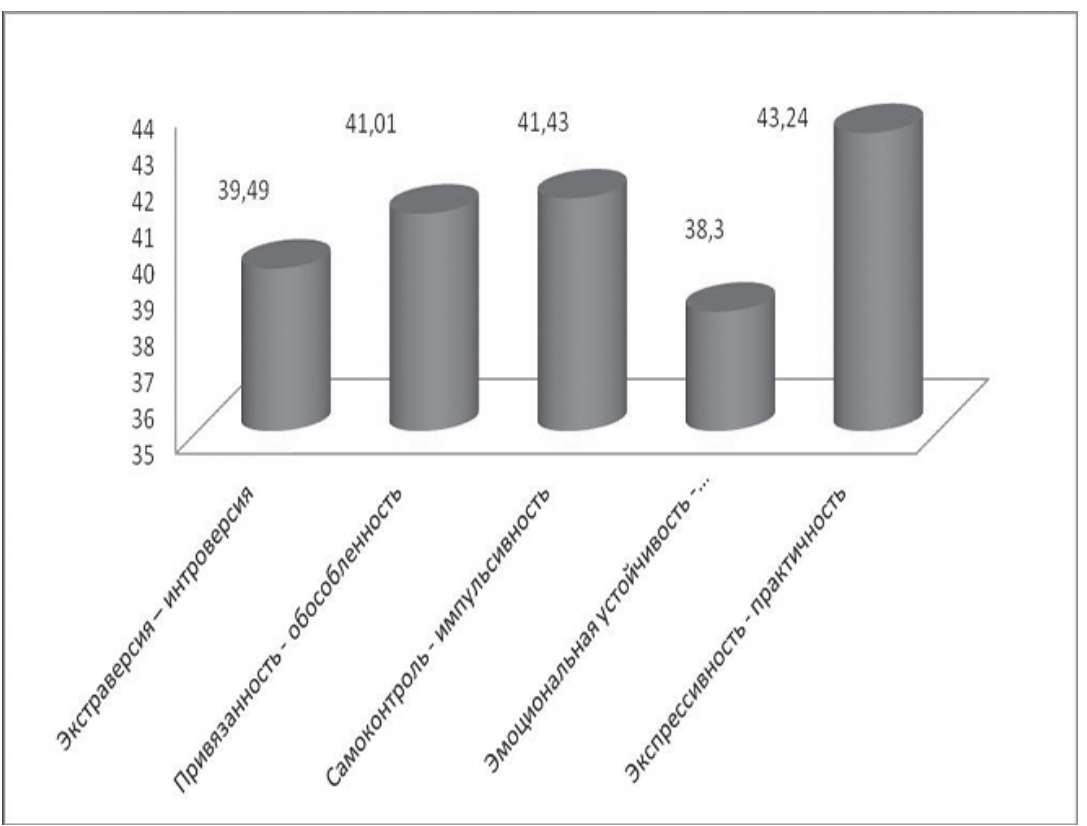

Рисунок 3. Средние показатели по основным факторам «Большой пятерки»

Для студенческой аудитории свойственны низкие показатели по первому фактору «Экстраверсия - интроверсия» $(39,49)$ и четвертому фактору «Эмоциональная устойчивость - эмоциональная неустойчивость» $(38,3)$, что свидетельствует о преобладании интроверсии и эмоциональной неустойчивости как свойств личности данной группы. Средние показатели характерны для второго фактора «Привязанность - обособленность» $(41,01)$, третьего фактора «Самоконтроль - импульсивность» $(41,43)$ и пятого фактора «Экспрессивность - практичность», что говорит о направленности на взаимодействие с другими, о склонности к волевому поведению и вместе с тем о легкости в восприятии жизненных проблем и интересе к разным сторонам жизнедеятельности. Математическая обработка данных с помощью критерия Фридмана выявила статистически значимые различия $\left(\chi_{r}^{2}=71.77 ; p=0\right)$.

Корреляционный анализ результатов исследования стратегий сетевой активности и основных факторов студентов с помощью коэффициента ранговой корреляции Спирмена показал следующие достоверные взаимосвязи (см. таблицу 1). 


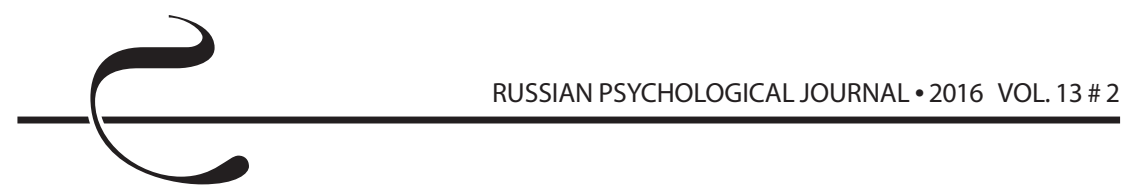

Таблица 1.

Корреляционные связи стратегий сетевой активности с основными личностными факторами ( $\mathrm{N}=260)$

\begin{tabular}{|c|c|c|c|}
\hline \multirow{2}{*}{ Факторы } & \multicolumn{3}{|c|}{ Cттратегии сетевой активности } \\
\cline { 2 - 4 } & $\begin{array}{c}\text { Активность в } \\
\text { действии }\end{array}$ & $\begin{array}{c}\text { Активность } \\
\text { в восприятии } \\
\text { альтернатив }\end{array}$ & $\begin{array}{c}\text { Интернет- } \\
\text { зависимость }\end{array}$ \\
\hline $\begin{array}{c}\text { Экстраверсия - } \\
\text { интроверсия }\end{array}$ & $\begin{array}{c}\mathbf{0 , 1 2 6 *} \\
\mathbf{p = 0 , 0 4 1}\end{array}$ & \\
\hline $\begin{array}{c}\text { Привязанность - } \\
\text { обособленность }\end{array}$ & & $\begin{array}{c}\mathbf{0 , 1 2 8 *} \\
\mathbf{p = 0 , 0 3 9}\end{array}$ \\
\hline $\begin{array}{c}\text { Самоконтроль - } \\
\text { импульсивность }\end{array}$ & & $\begin{array}{c}\mathbf{0 , 2 2 0} * \\
\mathbf{p = 0 , 0}\end{array}$ \\
\hline
\end{tabular}

Положительная взаимосвязь стратегии «Активность в восприятии альтернатив» с фактором «Экстраверсия - интроверсия» показывает, что чем больше выражено стремление реализовать идеальное Я в Интернете, тем характернее интровертированное поведение в этой среде, следование своим интересам, неактивное общение с другими участниками взаимодействия. Стратегия «Интернет-зависимость» имеет отрицательные взаимосвязи с факторами «Привязанность - обособленность» и «Самоконтроль - импульсивность». Студенты, проявляющие склонность к Интернет-зависимости, демонстрируют более независимое, самодостаточное, обособленное, беспечное поведение, без перспектив на будущее.

\section{Обсуждение результатов}

Для сетевых участников с высокими показателями «активности в восприятии альтернатив», с одной стороны, характерно то, что стремление реализовать идеальное Я в Интернете не является единственным регулятором их поведения; с другой стороны, они проявляют желание испытать некий новый опыт, который они не могут испытать в реальном общении. «Активность в восприятии альтернатив» проявляется в интересе читать чужие сообщения, просматривать сайты, порталы разного информационного содержания, выражать оценочное отношение к фото- или видеоматериалу.

Стратегия «Активность в действии» связана с характеристикой самокатегоризации. Высокие значения по данному виду активности говорят о слабой выраженности социально-ролевой составляющей в идентичности 
пользователя. В сети респонденты с данной выраженной стратегией знакомятся первыми, предлагают свою тему для обсуждения, обычно выходят в сеть, нечетко представляя свой личный статус.

Особенностями идентичности пользователей, склонных к Интернетзависимости, являются стремление избавиться от требований социального окружения и потребность в эмоциональной поддержке [5].

Обобщенные профили основных типов сетевой активности с позиции особенностей личности студентов можно представить следующим образом.

«Активность в действии» связана с такими особенностями студентов, как самопринятие, экстраверсия, общительность. Пользователи, выбирающие в качестве стратегии поведения в Интернете активность в действии, отличаются позитивным отношением к себе, принятием своих хороших и плохих качеств, положительной оценкой своего прошлого, высокой социальной активностью и яркой выраженностью проявления чувств, тенденцией самоутверждения и активной самореализации, эгоцентризмом.

«Активность в восприятии альтернатив» связана с такими особенностями, как интроверсия, ригидность, достаточно высокий уровень нейротизма. Это студенты с богатой интрапсихической активностью, выраженной изменчивостью настроения, чертами демонстративности. Для них характерны неспособность держаться выбранной линии поведения, зависимость от внешних обстоятельств, недостаточный самоконтроль.

Образ Я студента, склонного к Интернет-зависимости, можно представить следующим образом. Личность, которая критически относится к себе, скорее интроверт, чем экстраверт, с высоким уровнем нейротизма, неудовлетворенный собой (отсюда зависимость от внешних оценок и обстоятельств), нерешительный, задумчивый, тревожный, обособленный. Склонность к Интернет-зависимости связана с такими особенностями, как агрессивность, спонтанность, эмоциональная неустойчивость. Среди пользователей, склонных к Интернет-зависимости, наблюдаются низкая социальная активность и низкая выраженность проявления чувств, непринятие своих хороших и плохих качеств, низкая тенденция самоутверждения и активной самореализации.

\section{Заключение}

Сетевое пространство, по сравнению с реальным социальным окружением, представляет современной молодежной аудитории разные возможности для проявления индивидуально-личностных особенностей, создает условия вариативности самопрезентации, активности. Оно выступает уже как информационно-психологическое пространство, в котором наиболее рельефно проявляется влияние личностных детерминант на стратегии поведения. 


\section{Литература}

1. Асмолов А. Г. Культурно-историческая психология и конструирование миров. - М.: Изд-во Института практической психологии. - Воронеж: НПО «МОДЭК», 1996. - 768 с.

2. Бабаева Ю. Д., Войскунский А. Е., Смыслова О. В. Интернет: воздействие на личность. Психология зависимости: Хрестоматия / Сост. К. В. Сельченок. - Мн.: Харвест, 2004. - 592 с.

3. Белинская Е. П. Психология Интернет-коммуникации: учебное пособие. - М.: Изд-во МПСУ; Воронеж: МОДЭК, 2013. - 192 с.

4. Жичкина А. Е. Взаимосвязь идентичности и поведения в Интернете пользователей юношеского возраста: автореф. дисс. ... канд. психол. наук. - М., 2001.

5. Ивашенко А. В., Карабущенко Н. Б., Сунгурова Н. Л., Пилишвили Т. С., Чхиквадзе Т. В., Хворова Е. М. Личностные особенности студентов в сетевом взаимодействии // Humanitarian Bulletin SU "Pereyaslav-Khmelnitsky Pedagogical University by H. Skovoroda" - 2015. - Supplement 1 to V. 36, V. VI (66). - C. 588-598.

6. Климов Е. А. Индивидуальный стиль деятельности // Психология индивидуальных различий. Тексты / Под ред. Ю. Б. Гиппенрейтер, В. Я. Романова. - М., 1982. - С. 74-77.

7. Костюк Т. В. Проблема индивидуальных особенностей личности и различные варианты ее решения в психологии // Психология и школа. 2004. - № 3. - C. 3-23.

8. Кузнецова Ю. М., Чудова Н. В. Психология жителей Интернета. - М.: Изд-во ЛКИ, 2011. - 224 с.

9. Мерлин В. С. Психология индивидуальности / Под ред. Е. А. Климова. - М.: Изд-во Института практической психологии. - Воронеж: ВПО «МОДЭК», 1996. - 448 с.

10. Мироненко И. А. Современные теории в психологии личности. - СПб.: Изд-во Михайлова В. А., 2003. - 224 с.

11. Психологическая наука в России XX столетия: проблемы теории и истории / Под ред. А. В. Брушлинского. - М.: Изд-во РАН, 1997. - 576 с.

12. Психология индивидуальности: Новые модели и концепции / Под науч. ред. Е. Б. Старовойтенко, В. Д. Шадрикова. - М.: Изд-во НОУ ВПО МПСИ, 2009. - 384 с.

13. Смирнов С. А. Человек перехода // Кентавр. Методологический и игротехнический альманах. - 2003. - № 32. - С. 29-36.

14. Сунгурова Н. Л. Виртуальная самопрезентация личности: гендерный аспект // Психология и педагогика XXI века: теория, практика и перспективы: монография / Под общ. ред. Н. Б. Карабущенко, Н. Л. Сунгу- 
ровой. - М.: Изд-во РУДН, 2015. - С. 316-329.

15. Сунгурова Н. Л. Индивидуально-личностные особенности студентов в информационно-психологическом пространстве. - М.: Изд-во РУДН, 2014. - $170 \mathrm{c}$.

16. Сунгурова Н. Л. Личностно-типологические особенности студентов в компьютерно-опосредованной коммуникации // Актуальные проблемы психологии и педагогики в современном мире. Сборник научных трудов участников II Международной научно-практической конференции. - М.: Изд-во РУДН, 2015. - С. 294-299.

17. Шевченко И. С. Исследование самопрезентации личности в Интернетобщении: дисс. ... канд. психол. наук. - М., 2003.

18. GraffM. Individual differences in hypertext browsing strategies // Behaviour \& Information technology. - 2005. - V. 24. - pp. 93-99.

19. Holland N. The Internet regression // URL: www.rider.edu/users/suler/ psycyber/holland.html

20. Sungurova N., Karabuschenko N. Psychological Features of the Interaction of Students in Information Educational Space // EUROPEAN HUMANITIES STUDIES: State and Society / EUROPEJSKIE STUDIA HUMANISTYCZNE: Państwo i Społeczeństwo. - 2014-2015. - no. 1. - pp. 170-180.

21. Temple L., Lips H. M. Gender differences in Internet usage and task preferences // Behavior \& Information Technology. - 2000. - V. 19. - pp. 283-295.

22. Turkle Sh. Constructions and Reconstructions of the Self in Virtual Reality // Massachusetts Institute of Technology. Identity workshop // URL: http:// www.pscw.uva.nl/sociosite/psyberspace.html

23. Turkle Sh. The Second Self: Computers and Human Spirit. - N. Y.: Simon and Schuster, 1984.

24. Young Kimberly S. Caught in the Net. How to Recognize the signs of Internet Addiction And a Winning strategy for Recovery // URL: http:// www. netaddiction.com/infidelity_online.htm 